Check for updates

Montreal

Cite this as: BMJ 2021;375:n2984

http://dx.doi.org/10.1136/bmi.n2984

Published: 02 December 2021

\section{Covid-19: FDA expert panel recommends authorising molnupiravir but also voices concerns}

\author{
Owen Dyer
}

An advisory panel of experts has voted by 13 to 10 to recommend that the US Food and Drug Administration should grant an emergency authorisation to Merck's molnupiravir (Lagevrio), an antiviral for the outpatient treatment of covid-19. If the regulator follows the recommendation molnupiravir could be authorised within days.

The FDA has generally followed its panels' recommendations in the past, but the vote on molnupiravir was unusual for its narrow margin and the many reservations expressed by panellists who voted to recommend the drug. The nine hour meeting was broadcast live on YouTube. ${ }^{1}$

Molnupiravir was billed in press releases by Merck as having reduced hospital admissions by $50 \%$ in a phase III trial. That was the benefit cited by regulators in the UK, the first country to authorise the drug's use last month. ${ }^{2}$ But the data presented to the FDA panel showed only a 30\% reduction in admissions, a change that several panellists said was poorly explained.

The US has already authorised three monoclonal antibody cocktails, which have shown efficacy above $60 \%$ in preventing admission, and the FDA does not generally approve drugs that are less efficacious than those already in use.

However, these treatments are expensive and in limited supply and must be given by infusion in a healthcare setting. Regeneron, maker of the most used monoclonal, REGEN-COV, said this week that early testing suggested that its efficacy was reduced against the omicron variant. ${ }^{3}$ Molnupiravir is a course of pills that can be taken at home and costs one third of the price of REGEN-COV. Merck plans to manufacture 10 million courses by the end of 2021, a factor that weighed heavily on panellists' minds with a winter surge looming. The US has pre-ordered 3.1 million courses.

Several panellists who voted to recommend molnupiravir added qualifications and caveats or described it as a stopgap measure. An FDA panel is expected to consider an application for another new covid antiviral, Pfizer's Paxlovid, by the end of December. Pfizer has claimed that it is $89 \%$ effective in reducing hospital admission. ${ }^{4}$

\section{New data darken outlook}

Some members of the expert panel on molnupiravir expressed frustration at the quality of the data before them. In a briefing document they described an efficacy of $52 \%$ in preventing admission, based on interim analysis of 775 patients in the phase III trial. ${ }^{5}$ But a last minute addendum from the FDA noted that on 22 November "the Agency became aware of the topline safety and efficacy results from all 1433 randomised participants." 6 The full data showed more hospital admissions among patients taking molnupiravir (6.2\%) than among those taking a placebo $(4.7 \%)^{7}$ and led Merck to revise the benefit of preventing admission downwards to $30 \%{ }^{8}$

The interim results showed eight deaths in the placebo group and none in the molnupiravir group, but the post-interim results showed one death in each group. The trial stopped enrolment early after posting strong interim results.

When questioned why the trial's later participants showed such different outcomes than those in the interim analysis, a physician representing Merck told the panellists that the later group contained older patients, were more likely to be female and recruited from Europe, and more likely to carry the delta variant. But, he said, the drop in efficacy at the end of the trial "doesn't really add up to us."

\section{Genetic danger}

Molnupiravir attacks the coronavirus by triggering an accumulation of errors in the viral genome, and there have been concerns that it might alter human genes. But the panellists were shown data from animal studies that suggested low risk to adult humans at therapeutic doses. The drug will not be authorised in anyone who is pregnant or lactating, and its paediatric future is not clear.

Panellists were far less reassured about the drug's impact on coronavirus genes. While its mutagenic effect is designed to stop the virus replicating, mutations that make it more infective or vaccine resistant are also possible. In molnupiravir's phase II trial, 72 structural nucleotide changes to the spike protein were found in the treatment arm, compared with nine in the placebo arm.

Several of these changes were similar to those seen in major variants including delta, FDA researchers told the panel. But they stopped short of concluding that molnupiravir would increase the risk of new variants, noting that the coronavirus spike protein was already mutating in nature.

James Hildreth, president of Meharry Medical College in Tennessee, who ultimately voted no, said that Merck should do more to quantify the risk. "Even if the probability is very low, 1 in 10000 or 100000 , that this drug would induce an escape mutant which the vaccines we have do not cover, that would be catastrophic for the whole world," he said.

\footnotetext{
FDA. Antimicrobial Drugs Advisory Committee meeting. 30 Nov 2021. https://www.youtube.com/watch?v=fR9FNSJT64M

Mahase E. Covid-19: UK becomes first country to authorise antiviral
} molnupiravir. BM/2021;375:n2697. doi: 10.1136/bmi.n2697 pmid: 34737216 
3 Regeneron. Regeneron evaluating REGEN-COV and next generation antibodies against new omicron covid-19 variant. 30 Nov 2021. https://investor.regeneron.com/static-files/969bdb0b53f5-46c7-94fb-7473ee7f5be3

4 Mahase E. Covid-19: Pfizer's paxlovid is $89 \%$ effective in patients at risk of serious illness, company reports. BMJ2021;375:n2713. doi: 10.1136/bmj.n2713 pmid: 34750163

5 FDA. Briefing document: Antimicrobial Drugs Advisory Committee meeting. 30 Nov 2021. https://www.fda.gov/media/154418/download

6 FDA. Addendum to FDA briefing document: Antimicrobial Drugs Advisory Committee meeting. 30 Nov 2021. https://www.fda.gov/media/154419/download

7 Farley J. FDA introductory remarks: Antimicrobial Drugs Advisory Committee meeting. 30 Nov 2021. https://www.fda.gov/media/154473/download

8 Merck. Merck and Ridgeback Biotherapeutics provide update on results from MOVe-OUT study of molnupiravir, an investigational oral antiviral medicine, in at risk adults with mild-to-moderate covid-19. 26 Nov 2021. https://www.merck.com/news/merck-and-ridgeback-biotherapeuticsprovide-update-on-results-from-move-out-study-of-molnupiravir-an-investigational-oral-antiviralmedicine-in-at-risk-adults-with-mild-to-moderate-covid-19/

This article is made freely available for use in accordance with BMJ's website terms and conditions for the duration of the covid-19 pandemic or until otherwise determined by BMJ. You may use, download and print the article for any lawful, non-commercial purpose (including text and data mining) provided that all copyright notices and trade marks are retained. 